\title{
Peroxiredoxin 1 promotes invasion and migration by regulating epithelial-to-mesenchymal transition during oral carcinogenesis
}

\author{
Wenwen Niu ${ }^{1,}{ }^{,}$, Min Zhang ${ }^{1,}{ }^{,}$, Hui Chen ${ }^{1}$, Chunxiao Wang ${ }^{1}$, Ni Shi ${ }^{2}$, Xinying Jing ${ }^{1}$, \\ Lihua Ge ${ }^{1}$, Tong Chen ${ }^{2, \#}$, Xiaofei Tang ${ }^{1, \#}$ \\ ${ }^{1}$ Division of Oral Pathology, Beijing Institute of Dental Research, Beijing Stomatological Hospital and School of Stomatology, \\ Capital Medical University, Dongcheng District, Beijing, China \\ ${ }^{2}$ Division of Medical Oncology, Department of Internal Medicine, The Arthur G. James Cancer Hospital and Richard J. Solove \\ Research Institute, The Ohio State University, Columbus, Ohio, USA \\ *These authors contributed equally to this work \\ \#These authors shared senior authorship
}

Correspondence to: Xiaofei Tang, email: xftang10@ccmu.edu.cn Tong Chen, email: tong.chen@osumc.edu

Keywords: peroxiredoxin 1, NFKB, oral squamous cell carcinoma, epithelial-to-mesenchymal transition, nicotine Received: September 02, 2015

Accepted: May 20, 2016

Published: May 30, 2016

\section{ABSTRACT}

Tobacco smoking is the major risk factor for oral squamous cell carcinoma (OSCC). Previously, we found that nicotine up-regulates peroxiredoxin 1 (Prx1), an important antioxidant enzyme, and nuclear factor kappa B (NFKB) in OSCC cells. However, the molecular mechanism of Prx1 in oral carcinogenesis remains obscure. To improve our understanding of the functional role of Prx1 during the cascade of tobacco-associated oral carcinogenesis, we characterized Prx1, NFKB, and epithelialto-mesenchymal transition (EMT) markers including E-cadherin, vimentin and Snail in 30 primary oral tumors (15 from smokers with OSCC and 15 from non-smokers with OSCC) and 10 normal oral mucosa specimens from healthy individuals. The expression levels of Prx1, nuclear NFKB, vimentin and Snail were higher in the tumors from smokers with OSCC than in those from non-smokers with OSCC or the healthy controls. The expression levels of E-cadherin showed an opposite trend. Prx1 silencing suppressed the nicotine-induced EMT, cell invasion and migration in SCC15 cells in vitro. Furthermore, Prx1 activated the NFKB pathway in SCC15 cells. Prx1 might therefore play an oncogenic role in tobacco-related OSCC and thus serve as a target for chemopreventive and therapeutic interventions.

\section{INTRODUCTION}

Oral squamous cell carcinoma (OSCC) is the sixth most common cancer and represents a huge health burden worldwide [1]. The overall survival rate of patients with OSCC is low because of late diagnoses, low therapeutic response rates, and high recurrence [2]. Tobacco smoking is the major risk factor for OSCC and is associated with tumor development, invasion, and metastasis, which are responsible for the high recurrence and poor prognosis [3, 4].

Increasing evidence suggests that epithelial-tomesenchymal transition (EMT) contributes to the tumor metastatic cascade. EMT involves a series of morphological alterations (losses of cell-cell junctions and cell polarity) and molecular changes including the down-regulation of epithelial cell markers (e.g., E-cadherin) and the upregulation of mesenchymal adhesion and cytoskeletal proteins (e.g., vimentin) and transcription factors (e.g., Snail) $[5,6]$. Enhanced EMT is associated with poor overall and metastasis-free survival in OSCC [7]. Exposure to cigarette-smoke extract can promote the EMT process. The long-term use of nicotine can enhance the expression of Snail, an important EMT regulator, in OSCC cells $[8,9]$.

Previously, we found that nicotine up-regulates peroxiredoxin 1 (Prx1). Prx1 overexpression was associated with poor prognosis and tumor growth in a xenograft model [10-12]. Prx1 is a major 2-Cys member of the peroxiredoxin family. Aberrant Prx1 expression is reported in numerous cancers including OSCC and cancers of the breast, thyroid, lung, bladder, and prostate [13-18]. 
The primary biochemical function of Prx 1 appears to be peroxide detoxification and reactive oxygen-species scavenging [19]. Prx1 also acts as a molecular chaperone to regulate cell proliferation, differentiation, and apoptosis under stressful conditions [20, 21]. In addition, Prx1 can increase microvascular invasion and tumor-node metastasis. Prx1 stimulates endothelial cell proliferation, migration, and differentiation depending on Toll-like receptor 4 and vascular endothelial growth factors $[22,23]$. Studies suggest that Prx1 modulates transforming growth factorbeta 1-induced EMT through its peroxidase activity [24]. Our former study verified that Prx1 regulates the translocation and DNA-binding activity of nuclear factor kappa $\mathrm{B}(\mathrm{NF} \kappa \mathrm{B})$ in oral cancer cells. NFкB signaling plays an important role in the EMT process by regulating the EMT-related transcriptional factor ZEB1, Snail, and other proteins $[25,26]$. Therefore, we hypothesize that nicotine induces EMT in oral cancer by activating the Prx1 and $\mathrm{NF} \kappa \mathrm{B}$ cascade.

The objective of this study was to improve our understanding of the functional role of Prx 1 during nicotine-associated invasion and migration in OSCC. We first compared Prx1 expression between smokers with OSCC and non-smokers with OSCC. We then examined the effect of tobacco smoke on EMT in patients with OSCC. Next, we knocked down Prx1 in an OSCC cell line and determined the effect of the knockdown on oral squamous-cell invasion and migration and the EMT process. Finally, we investigated the effect of Prx1 on the NFKB activation. Our results demonstrate that Prx 1 might serve as a novel biomarker and play a critical role in tobacco-related OSCC.

\section{RESULTS}

\section{Prx1 is overexpressed in human OSCC tissues}

We detected Prx1 expression in oral-mucosa specimens obtained from 15 smokers with OSCC, 15 non-smokers with OSCC, and 10 healthy individuals. The Prx1 mRNA expression level was significantly elevated in the smokers and non-smokers with OSCC compared with that in the healthy individuals (Figure 1A). Immunohistochemistry analysis revealed comparable levels of Prx1 protein overexpression among the same tissues (Figure 1B and 1C). The Prx1 expression was lowest in the healthy individuals, higher in the non-smokers with OSCC, and highest in the smokers with OSCC.

\section{The EMT markers E-cadherin, vimentin and Snail are altered in human OSCC tissues}

We characterized the expression of E-cadherin, vimentin and Snail in oral mucosa specimens. The smokers and non-smokers with OSCC had lower expression levels of E-cadherin mRNA and higher expression levels of vimentin and Snail mRNAs compared with the healthy individuals (Figure 1A). The immunoreactivities for vimentin and Snail were lowest in the healthy individuals, higher in the non-smokers with OSCC, and highest in the smokers with OSCC, whereas that for E-cadherin displayed the opposite trend (Figure 1B and 1C).

\section{Nicotine increases Prx1, the EMT process, cell invasion, and migration in vitro}

To determine whether nicotine can modulate Prx1, nicotinic acetylcholine receptor (nAChR), and the EMT process, we assessed the mRNA and protein expression of Prx1, $\alpha 3$ nAChR, $\alpha 7$ nAChR, and EMT markers (E-cadherin, vimentin and Snail) in SCC15 cells exposed to nicotine. Nicotine increased the mRNA and protein expression of Prx1, $\alpha 3$ nAChR, $\alpha 7 \mathrm{nAChR}$, vimentin and Snail, and reduced the mRNA and protein expression of E-cadherin compared with that in control cells (Figure 2A and 2B).

We performed a Matrigel invasion assay to evaluate squamous-cell invasion after nicotine exposure. More SCC15 cells penetrated through the filters after the nicotine treatment compared with control cells (Figure 2C). We performed a wound-healing assay to determine whether nicotine can promote SCC15 cell mobility. Compared with those of control cells, the healing and migration rates of nicotine-treated SCC15 cells increased after 12 and $24 \mathrm{~h}$, respectively (Figure 2D).

\section{Prx1 knockdown inhibits nicotine-induced EMT, cell invasion, and migration in vitro}

Prx1 knockdown enhanced the nicotine-induced reduction of E-cadherin expression $(P<0.05)$ and decreased the nicotine-induced overexpression of vimentin and Snail $(P<0.01$; Figure $3 \mathrm{~A}$ and $3 \mathrm{~B})$. Moreover, Prx 1 knockdown reduced the rates of nicotine-induced cell invasion and migration (Figure $3 \mathrm{C}$ and $3 \mathrm{D}$ ).

\section{Prx1 activates NFkB signaling and promotes EMT, cell invasion, and migration in vitro}

To investigate whether Prx1 modulates EMT in OSCC, we monitored E-cadherin, vimentin and Snail in SCC15 cells that were transfected with Prx1 overexpression plasmid or Prx1 shRNA. We first confirmed the alteration of Prx1 after transfection by real-time PCR and western blot (Figure 4A and 4B). Transfection with the Prx1 overexpression plasmid decreased the expression of E-cadherin and increased the expression of vimentin and Snail. In contrast, transfection with the Prxl shRNA increased the expression of E-cadherin and decreased the expression of vimentin and Snail (Figure 4A and 4B).

To further explore the molecular mechanisms responsible for Prx1-mediated EMT, we examined the activation of $\mathrm{NF \kappa B}$ in SCC15 cells with altered Prx1

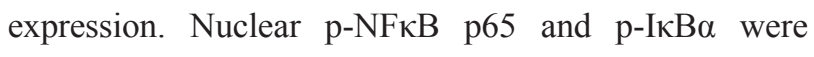


A
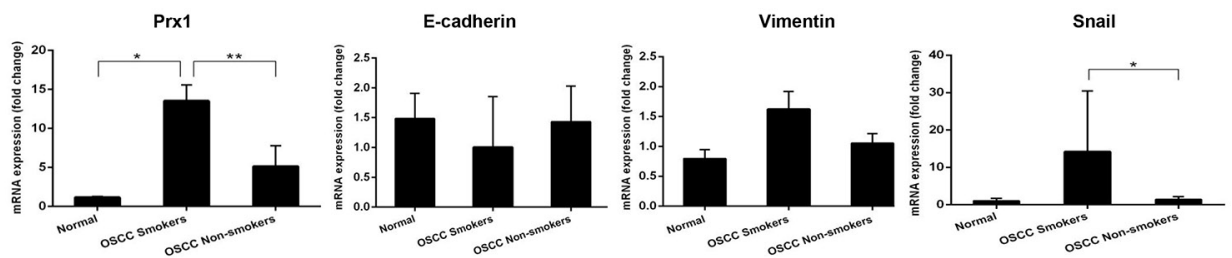

B

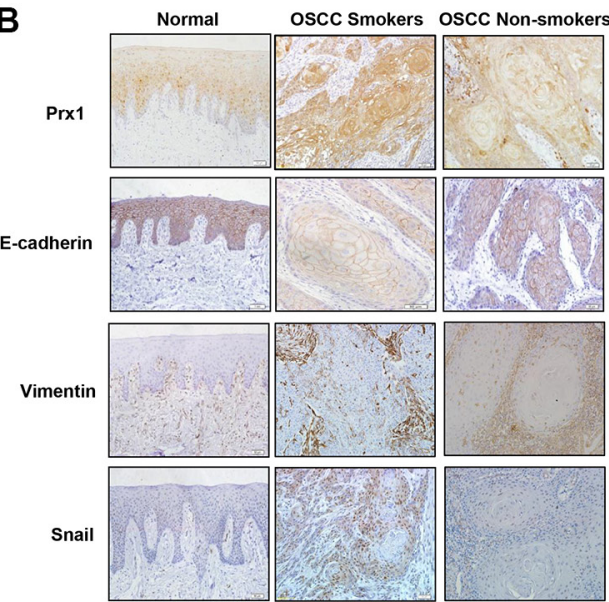

C
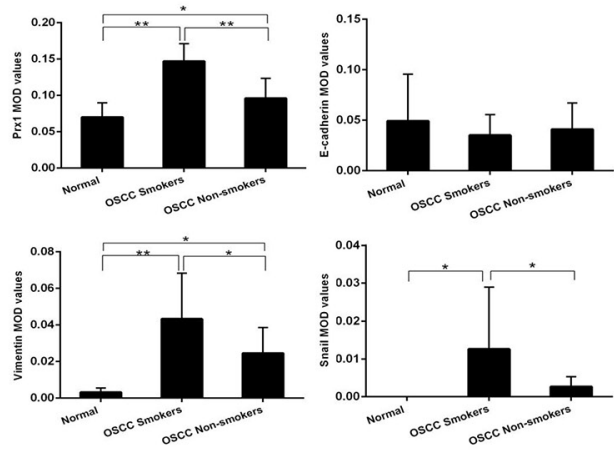

Figure 1: Expression of Prx1 and EMT markers in human OSCC tissues. (A) mRNA expression of Prx1, E-cadherin, vimentin and Snail in human oral mucosa specimens detected by real-time PCR; (B) representative immunohistochemistry images of Prx1, E-cadherin, vimentin and Snail in tumors and normal tissues (200× magnification); and (C) immunohistochemistry scores analyzed by mean optical density (MOD). The values are expressed as the mean \pm SE. $* P<0.05 ; * * P<0.01$.

A

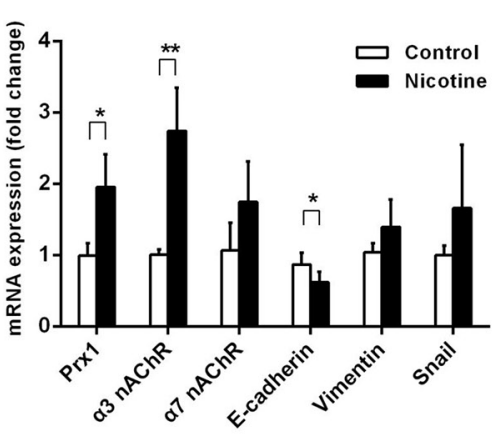

C
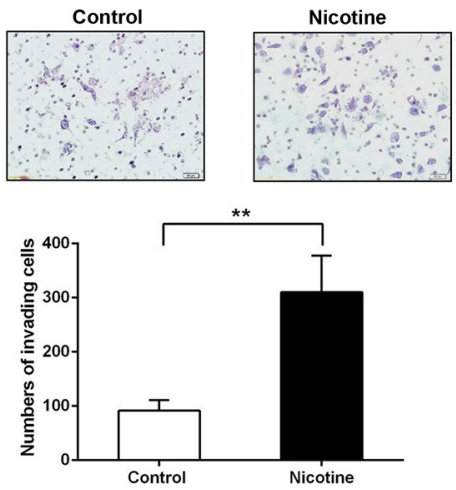

B

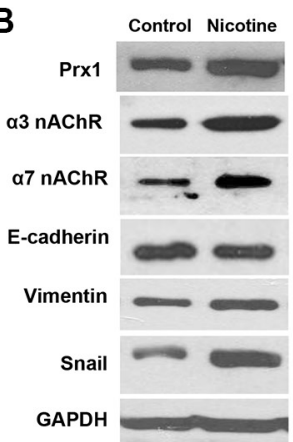

D
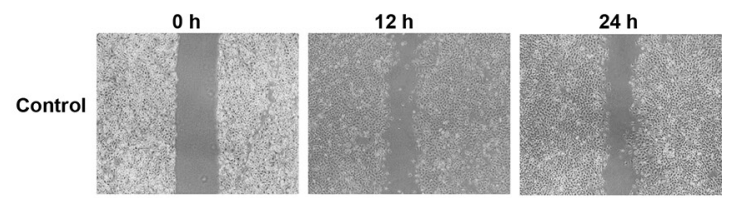

Nicotine
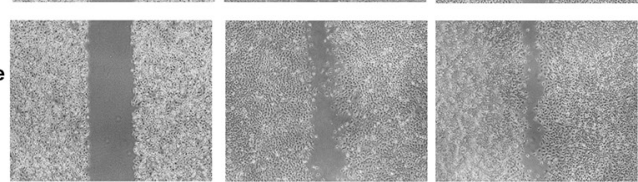

Figure 2: Nicotine up-regulates Prx1, $\alpha 3$ nAChR and $\alpha 7 \mathrm{nAChR}$, enhances EMT, and promotes invasion and migration in SCC15 cells. (A) mRNA expression of Prx 1, $\alpha 3 \mathrm{nAChR}, \alpha 7 \mathrm{nAChR}$, E-cadherin, vimentin and Snail in control and nicotine-treated SCC15 cells; (B) representative blots from one of three separate experiments for the protein expression of Prx1, $\alpha 3 \mathrm{nAChR}, \alpha 7 \mathrm{nAChR}$, E-cadherin, vimentin and Snail in control and nicotine-treated SCC15 cells; (C) images of invading control and nicotine-treated SCC15 cells detected by Matrigel invasion assay (upper panel) and statistical analysis (lower panel); and (D) wound healing assay to examine the effect of nicotine on SCC15 cell mobility. The values are expressed as the mean \pm SE. $* P<0.05 ; * * P<0.01$. 
significantly up-regulated in Prx1-overexpressed cells. Prx1 knockdown dramatically decreased expression levels

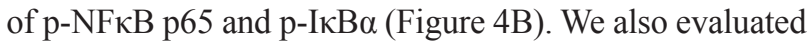
$\mathrm{NF} \kappa \mathrm{B}$ in human OSCC tissues. IHC staining indicated that the nuclear NF $\kappa \mathrm{B}$ expression in oral mucosa was lowest in the healthy control tissues, higher in the non-smokers with OSCC, and highest in the smokers with OSCC, which is similar to the Prx 1 expression pattern (Figure 4C and 4D).

We conducted further Matrigel invasion and wound-healing assays using SCC15 cells with altered Prx1 expression. More Prx1-overexpressed cells than control cells penetrated through the filters after $24 \mathrm{~h}$. Prx1 knockdown decreased the number of invading cells (Figure 5A and 5B). Similarly, the healing and migration rates of SCC15 cells were increased by Prx 1 overexpression and decreased by Prx 1 silencing compared with those of control cells (Figure 5C).

\section{DISCUSSION}

Nicotine can induce cell proliferation, invasion, and metastasis in several cancers $[27,28]$. Nicotine-induced

A

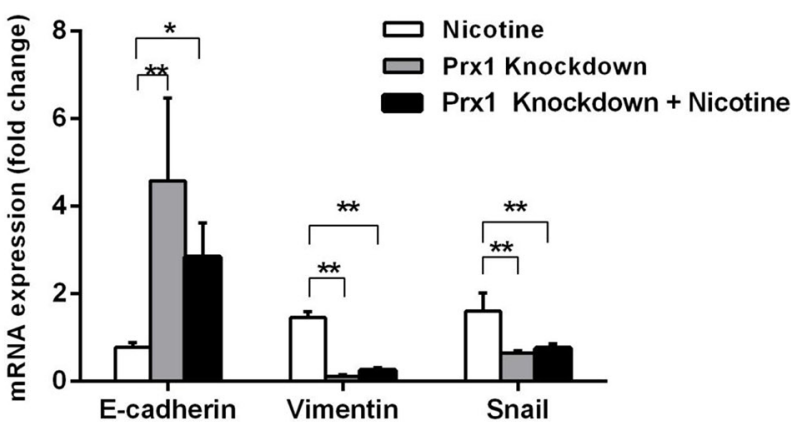

C

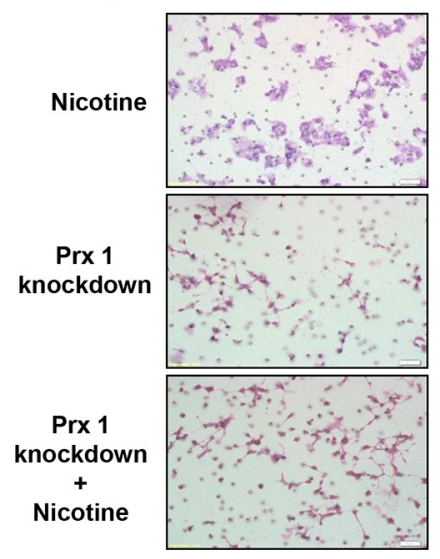

Prx 1 overexpression correlates significantly with OSCC carcinogenesis $[12,29]$, and further investigation of the functional role of Prx1 could provide a novel biomarker for OSCC prevention and therapy.

Nicotine exhibits its pathobiological effects by displacing the local cytotransmitter acetylcholine from the nAChR expressed on the surface of oral epithelial cells $[30,31]$. The nAChR subunit family is composed of 17 members: $\alpha 1-\alpha 10, \beta 1-\beta 4, \delta, \gamma$, and $\varepsilon$. The $\alpha 3, \alpha 5, \alpha 7$, $\alpha 9, \beta 2$, and $\beta 4$ subunits are found in human oral epithelial cells. $\alpha 7 \mathrm{nAChR}$ is the main subtype receptor for tobacco products, and $\alpha 3 \mathrm{nAChR}$ is another key receptor in oral epithelial cells $[31,32]$. The inhibition of $\alpha 7 \mathrm{nAChR}$ might provide a feasible approach for preventing the progression of head and neck cancer [33]. Previously, we showed that the oral cancer tissues of smokers had higher expression of $\alpha 3$ and $\alpha 7 \mathrm{nAChR}$ compared with that of non-smokers [34]. Together with those results, the overexpression of $\alpha 3$ and $\alpha 7 \mathrm{nAChR}$ in SCC15 cells exposed to nicotine suggests that nicotine might up-regulate Prx1 through $\alpha 3$ and $\alpha 7 \mathrm{nAChR}$ activation and thus serves as a tumor promoter in OSCC.

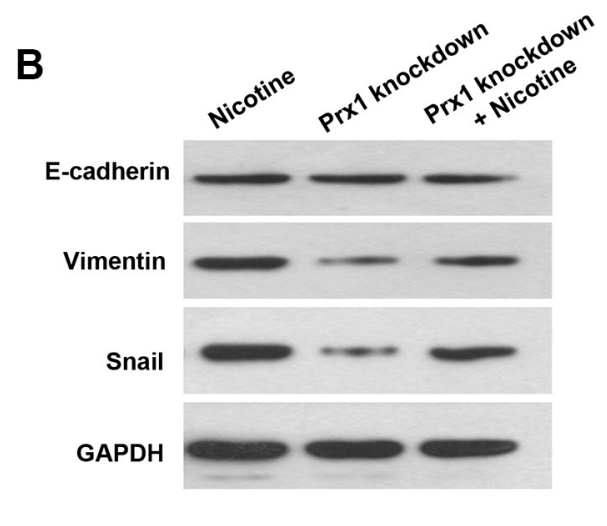

D
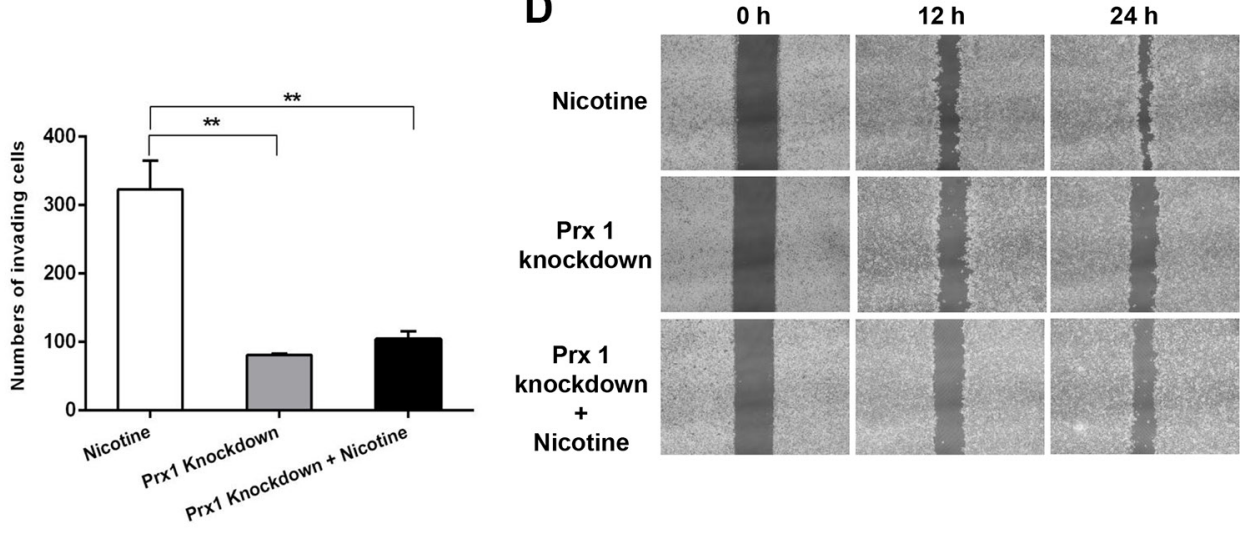

Figure 3: Effects of Prx1 knockdown on nicotine-induced EMT, invasion, and migration in SCC15 cells. mRNA (A) and protein (B) expression of E-cadherin, vimentin and Snail in nicotine-treated control cells, Prx1-knockdown cells, and Prx1-knockdown + nicotine cells. (C) images of the invading cells detected by Matrigel invasion assay (right panel) and statistical analysis (left panel); and (D) wound healing assay to examine the effect of Prx1 knockdown on SCC15 cells treated with nicotine. The values are expressed as the mean \pm SE. $* P<0.05 ; * * P<0.01$. 
Metastasis is essentially dependent on the EMT process $[5,6]$. During EMT, oral epithelial cells lose their specific phenotypes and develop features of mesenchymal cells. The tight-junction and adherens-junction proteins (e.g., E-cadherin) are down-regulated, while mesenchymal cell-specific proteins (e.g., vimentin) are up-regulated. EMT is enhanced by transcriptional repressors (e.g., Snail) that directly regulate genes involved in cellular adhesion, migration, and invasion $[35,36]$. The differential expression levels of Prx1, E-cadherin, vimentin and Snail between smokers and non-smokers with OSCC, and the effects of Prx1 silencing or Prx1 overexpression on the ability of nicotine to enhance EMT, invasion, and migration in SCC15 cells suggest that Prx1 is a key modulator in the nicotine-induced EMT process.

$\mathrm{NF} \kappa \mathrm{B}$ is an important transcription factor involved in oncogenic pathways including inflammation, cell differentiation, tumorigenesis, and EMT [37, 38]. For example, NF- $\kappa \mathrm{B}$ activation was needed for IL-17-induced
EMT, cell migration, and invasion in lung cancer [25]. Zipper-interacting protein kinase increased the expression of $\beta$ - catenin, Snail and Slug; decreased the expression of E-cadherin; and promoted EMT and metastasis by activating the NFKB pathway [26]. The relatively high expression levels of Prx 1 and NFKB in the oral mucosa of smokers with OSCC and the effects of Prx 1 alteration on $\mathrm{p}-\mathrm{I} \kappa \mathrm{B} \alpha$ and $\mathrm{NF} \kappa \mathrm{B}$ nuclear translocation indicate that with nicotine induction, Prx1 is overexpressed and activates $\mathrm{NF} \kappa \mathrm{B}$. The NF $\kappa \mathrm{B}$ translocates into the nucleus and regulates transcription factors such as Snail to alter the expression of the EMT marker genes E-cadherin and vimentin, resulting in increased invasiveness and migration. We elucidated this mechanism in Figure 6.

In conclusion, Prx 1 and $\mathrm{NF} \kappa \mathrm{B}$ were overexpressed in human oral cancer cells. The expression of Prx1 and $\mathrm{NF} \kappa \mathrm{B}$ in smokers with OSCC was significantly higher than that in non-smokers with OSCC. Prx 1 knockdown suppressed nicotine-induced cell invasion and migration
A
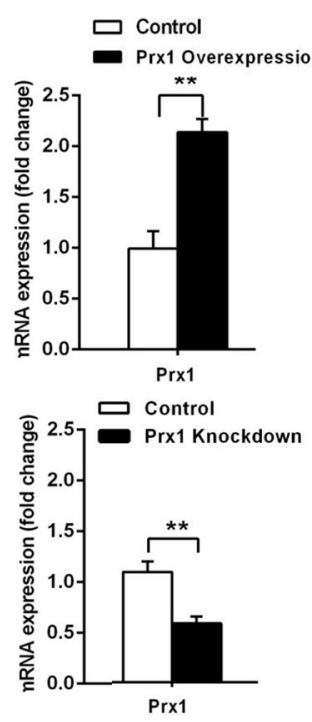

C

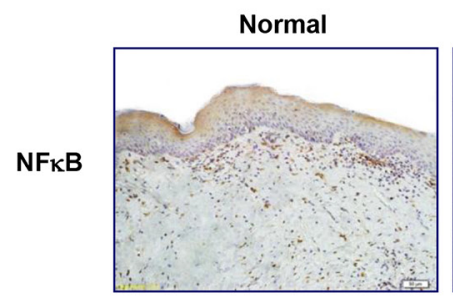

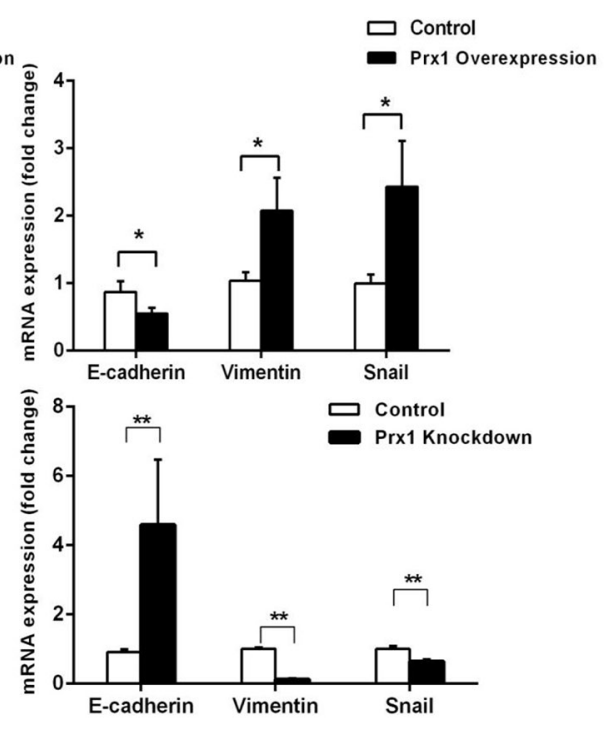

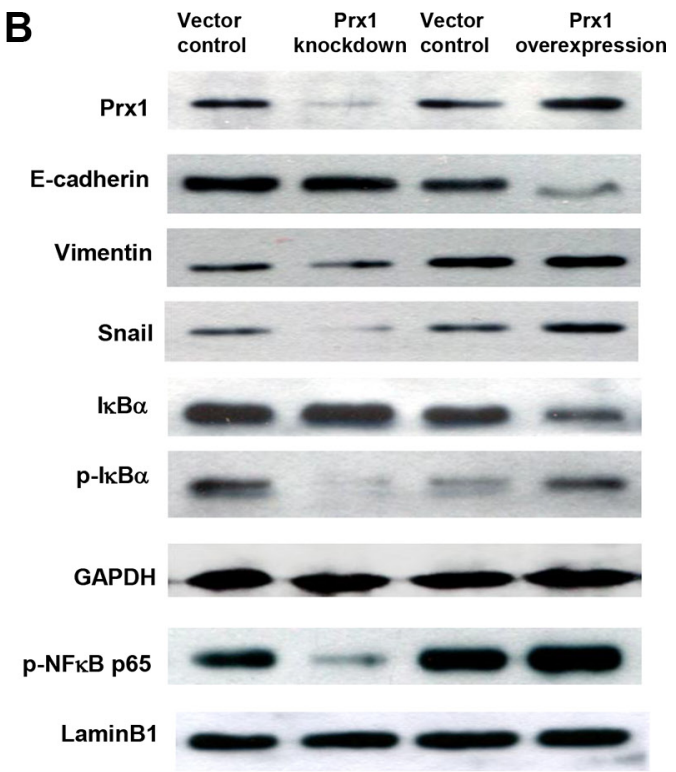


A
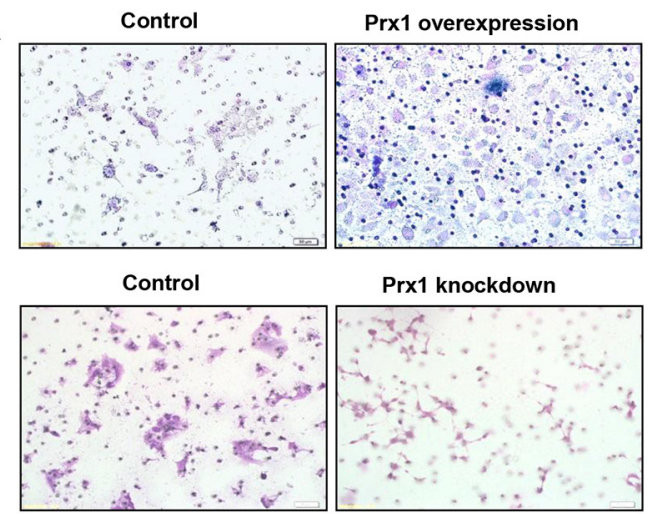

C

Vector control

Prx1 knockdown

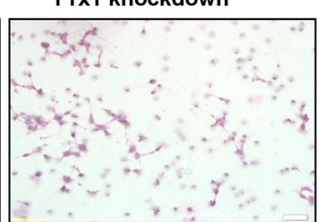

$\mathrm{Oh}$
B

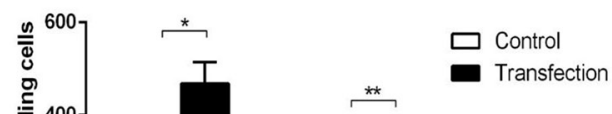

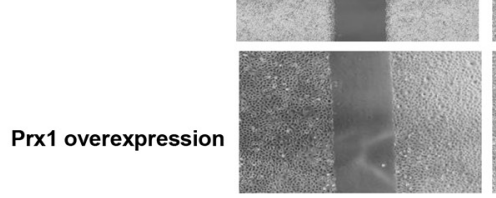

$12 \mathrm{~h}$

$24 \mathrm{~h}$
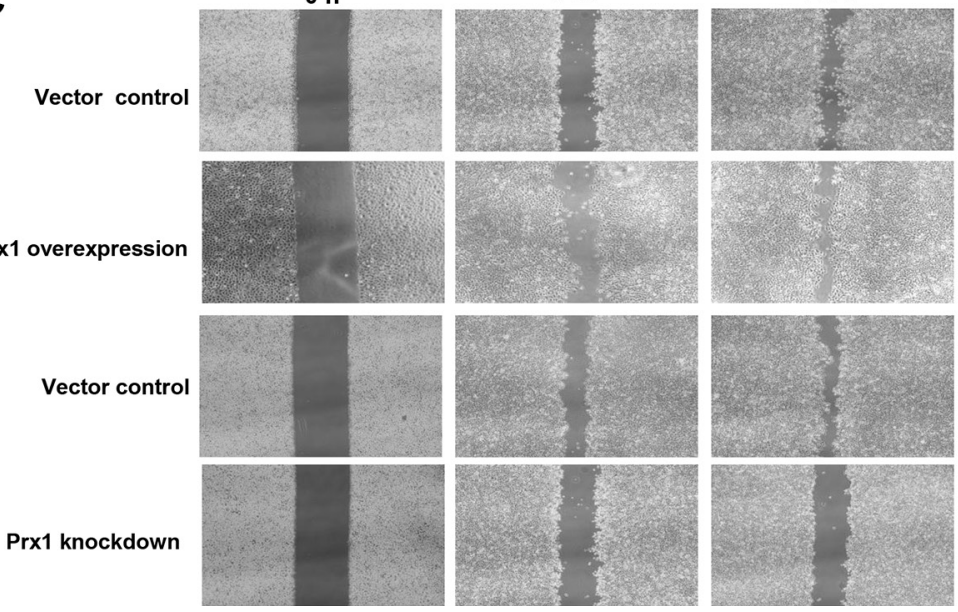

Figure 5: Oral squamous cell invasion and migration are altered by Prx1 in vitro. (A) images of invading SCC15 cells; (B) statistical analysis; and (C) wound healing assay to examine the effects of Prx1 overexpression and knockdown on SCC15 cell mobility. The values are expressed as the mean $\pm \mathrm{SE}$. ${ }^{*} P<0.05 ;{ }^{*} P<0.01$.

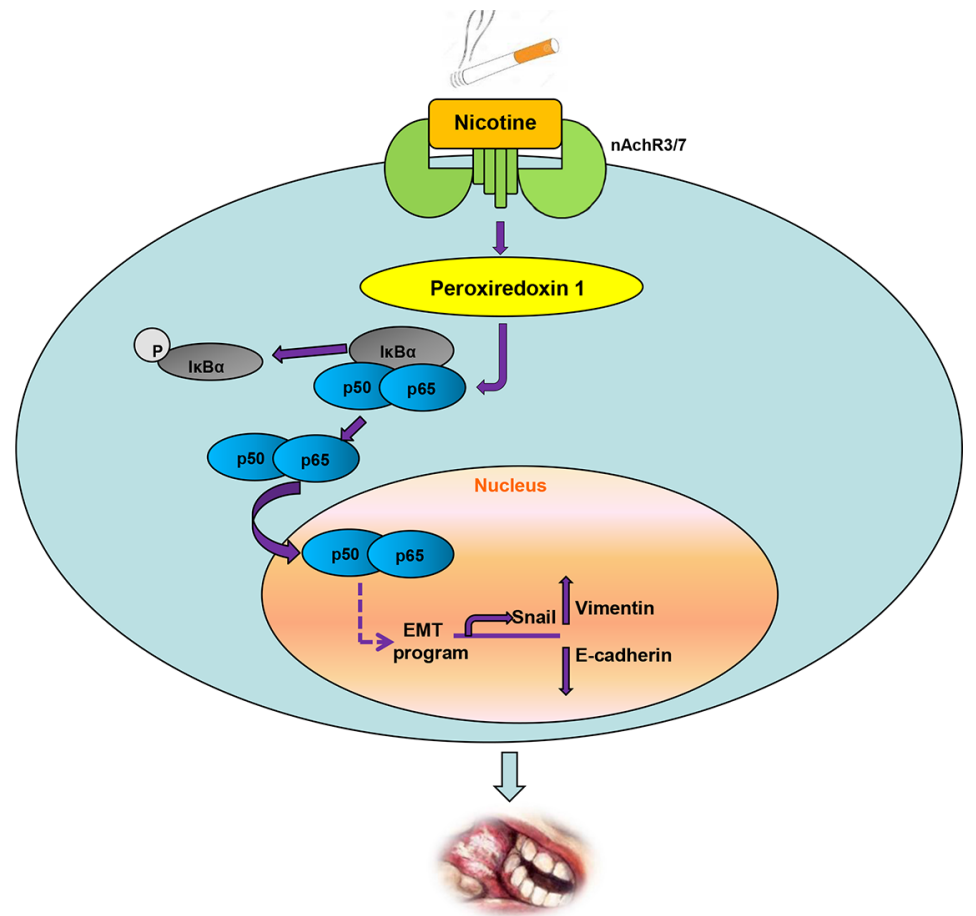

Figure 6: Schematic representation of up-regulation of Prx1 and activation of NFкB by nicotine to promote EMT in OSCC. 
by inhibiting the EMT process in vitro. Prx1 promotes the EMT process by activating NFKB activity. Our results suggest that Prx1 plays an oncogenic role in nicotine-enhanced EMT in OSCC. This information could be used to help develop preventive/therapeutic agents that target Prx1 in nicotine-associated diseases including OSCC.

\section{MATERIALS AND METHODS}

\section{Patients and tissue specimens}

The Human Research Ethics Committee of the Capital Medical University School of Stomatology approved all protocols involving human subjects. Informed consent was obtained for all investigations involving human subjects. Primary tumors and normal oral mucosa samples were obtained from 30 patients with OSCC (15 OSCC smokers and 15 non-smokers) and 10 healthy individuals who underwent maxillofacial plastic surgery at the hospital of the Capital Medical University School of Stomatology. All OSCC tissues were moderately to well differentiated. The patient characteristics and clinical information are summarized in Table 1. For histopathologic and immunohistochemical analyses, the oral mucosa specimens were collected immediately after surgical removal and fixed with $10 \%$ formalin followed by paraffin-embedding. For real-time PCR analysis, fresh specimens were frozen in liquid nitrogen and stored at $-80^{\circ} \mathrm{C}$ until further use.

\section{Immunohistochemistry}

Oral mucosa specimens were fixed in $10 \%$ neutralbuffered formalin overnight, embedded in paraffin, and serially sectioned at $4 \mu \mathrm{m}$ as described previously [12]. Deparaffinized sections were briefly heated for $10 \mathrm{~min}$ in a pressure cooker containing $10 \mathrm{mM}$ citrate buffer (pH 6.0) for antigen retrieval and then soaked in $3 \% \mathrm{H}_{2} \mathrm{O}_{2}$ in $0.1 \mathrm{M}$ TBS (pH 7.4) for $15 \mathrm{~min}$ to quench endogenous peroxidases. The sections were subsequently treated with protein block solution (Boshide, China) for $20 \mathrm{~min}$ and then incubated overnight at $4^{\circ} \mathrm{C}$ with antibody for Prx1, $\alpha 3$ nAChR, $\alpha 7$ nAChR, Snail (abcam, USA), E-cadherin (Cell Signalling Technology, USA), vimentin (Maixin, China), or p-NF-kB p65 (Cell Signalling Technology, USA). Incubation with primary antibody was followed by incubation for $30 \mathrm{~min}$ with horseradish peroxidase-linked secondary anti-rabbit GT Vision ${ }^{\mathrm{TM}}$ polymer (Gene Tech, USA). The sections were developed with diaminobenzidine (Gene Tech, USA) chromogen and then counterstained with hematoxylin, dehydrated, and mounted for Olympus BX61 microscope observation (Olympus, Tokyo, Japan). The mean optical density was determined by the mean value of positive expression counted in five randomly selected fields. The NFKB staining score (range 0-100) was determined and expressed the percentage of cells with positive $\mathrm{p}-\mathrm{NF}-\mathrm{kB}$ p65 expression.

\section{Quantitative real-time PCR}

Total RNA was extracted from oral-mucosa specimens or cells using TRIzol (Invitrogen Life Technologies, USA) according to the manufacturer's instructions. cDNA was synthesized using a High Capacity cDNA Reverse Transcription Kit (Applied Biosystems, USA). The expression of Prx1, $\alpha 3 \mathrm{nAChR}$, $\alpha 7 n A C h R$, E-cadherin, vimentin, Snail, and GAPDH was determined using SYBR Green. The primers for the genes of interest were: Prx1 (Forward 5'-gggtattcttcggcagatca-3', Reverse $5^{\prime}$-tccccatgttgtcagtgaa-3'), $\alpha 3 \mathrm{nAChR}$ (Forward 5'-GGACGGGATGTGTGGTTACT-3', Reverse 5'-TGG CTTCTTTGATTTCTGGTG-3'), $\alpha 7 \mathrm{nAChR}$ (Forward 5'-AAACTCACAGATGGGCAAGG-3', Reverse 5'-CCGT AAGCAACACGACTGAC-3'), E-cadherin (Forward 5'-TTGCTACTGGAACAGGGACA-3', Reverse 5'-GTAT TGGGAGGAAGGTCTGC-3'), vimentin (Forward 5'-GAA GAGAACTTTGCCGTTGA-3', Reverse 5'-CGAAGGTGA CGAGCCATT-3'), Snail (Forward 5'-TTACCTTCCAG CAGCCCTAC-3', Reverse 5'-GACAGAGTCCCAGATG AGCA-3'), and GAPDH (Forward 5'-AGGTCGGTGTGA ACGGATTTG-3', Reverse 5'-TGTAGACCATGTAGT TGAGGTCA-3'). Each sample was analyzed in triplicate on an ABI PRISM 7900 (Applied Biosystems).

\section{Cells and cell treatment}

The human OSCC cell line SCC15 was purchased from the American Type Culture Collection. SCC15 cells were cultured in a 1:1 mixture of Dulbecco's modified Eagle medium and Nutrient Mixture F-12 medium $+15 \%$ fetal bovine serum (FBS) (Gibco, USA) in a $37^{\circ} \mathrm{C}$ and $5 \%$ $\mathrm{CO}_{2}$ environment. The transfected and non-transfected SCC 15 cells $\left(1 \times 10^{6}\right)$ were treated with $1 \mu \mathrm{mol} / \mathrm{L}$ nicotine for 7 days.

\section{Plasmids and cell transfection}

To overexpress Prx1, SCC15 cells were transfected with pEZ-M02-PRX1 (GeneCopoeia, USA) or control plasmid (GeneCopoeia, USA) with Lipofectamine ${ }^{\mathrm{TM}} 2000$ (Invitrogen, USA) to $50 \%$ confluence on a 6-well plate. After transfection for $48 \mathrm{~h}$, stably transfected cells were selected using G418 (200 $\mu \mathrm{g} / \mathrm{ml})$ for 10 days. To knock down Prx1, SCC15 cells were transfected with Prx1 shRNA Plasmid (Santa Cruz Biotechnology) using Lipofectamine ${ }^{\mathrm{TM}} 2000$ (Invitrogen, USA). The shRNA Plasmid-A (Santa Cruz Biotechnology) was used as a control. The efficiency of Prx1 knockdown was determined by RT-PCR and western blot analysis.

\section{Western blot analysis}

Proteins were extracted from cells using immunoprecipitation assay buffer $(50 \mathrm{mM}$ Tris$\mathrm{Cl}, 1 \% \mathrm{NP} 40,150 \mathrm{mM} \mathrm{NaCl}, 1 \mathrm{mM}$ EDTA, $1 \mathrm{M}$ 
Table 1: Clinical characteristics of the patients with OSCC

OSCC Smokers

OSCC Non-smokers

\begin{tabular}{|l|c|c|}
\hline No. of patients & 15 & 15 \\
\hline Age & 50 & 60 \\
\hline Mean & $37-77$ & $49-75$ \\
\hline Range & & 11 \\
\hline Gender & 0 & 4 \\
\hline Female & 15 & \\
\hline Male & & 8 \\
\hline Grade & 5 & 2 \\
\hline Moderate & 8 & 5 \\
\hline Moderate-High & 2 & 0 \\
\hline High & & 1 \\
\hline Lesion Location & 3 & 3 \\
\hline Mouth floor & 3 & 8 \\
\hline Buccal & 4 & 3 \\
\hline Gingival & 4 & \\
\hline Tongue & 1 & \\
\hline Maxilla & & \\
\hline
\end{tabular}

phenylmethylsulfonyl fluoride, $10 \mu \mathrm{g}$ each of aprotinin and leupeptin, and $1 \mathrm{mM} \mathrm{Na3VO4).} \mathrm{The} \mathrm{protein} \mathrm{concentration}$ was determined using the Lowry method. Equal amounts of protein were separated on $12 \%$ SDS-PAGE gels and blotted onto nitrocellulose membranes. The blots were incubated with primary antibody for Prx $1, \alpha 3 \mathrm{nAChR}, \alpha 7$ nAChR, Snail (Abcam, USA), E-cadherin (Cell Signalling Technology, USA), vimentin (Bioss, China), IкB $\alpha, \mathrm{p}-\mathrm{I} \kappa \mathrm{B} \alpha$, p-NFkB p65 (Cell Signalling Technology, USA), or GAPDH (Sigma, USA). The immunoreactive bands were detected with horseradish peroxidase-conjugated secondary antibodies and enhanced chemiluminescence reagents (Amersham Biosciences, USA).

\section{Matrigel invasion assay}

Cell-invasion assays were performed in triplicate using 24-well Transwells (8-mm pore size; Corning, USA) coated with Matrigel ( $1 \mathrm{mg} / \mathrm{ml}$; BD, USA). SCC15 cells $\left(10^{5}\right.$ cells/well $)$ were seeded in the upper chambers in culture media containing $0.2 \%$ FBS. The lower chambers were filled with $500 \mu 1$ 10\% FBS medium to induce cell migration. Invasion assays were carried out for $24 \mathrm{~h}$ for Prx1-overexpressed cells and $48 \mathrm{~h}$ for Prx1-knockdown cells. Cells inside the chambers were removed with a cotton swab. The invading cells were stained with Haematoxylin (Salarbio, China) and examined by microscopy (Olympus IX71). Six randomly selected fields were photographed at $200 \times$ magnification, and the invading cells were counted. The average number of invading cells in each field represented the invasive ability.

\section{Wound healing assay}

After transfection with Prx1 overexpression plasmid or PrX1 shRNA, OSCC cells were wounded by a $10 \mu 1$ sterile pipette tip and washed in PBS to remove cellular debris. The cells were then cultured for $24 \mathrm{~h}$. The cells were photographed at 0,12 , and $24 \mathrm{~h}$ after wounding.

\section{Statistical analysis}

The mRNA and/or protein expression levels of Prx1, $\alpha 3 \mathrm{nAChR}, \alpha 7 \mathrm{nAChR}$, E-cadherin, vimentin, Snail, I $\kappa \mathrm{B} \alpha$ and $\mathrm{NF} \kappa \mathrm{B}$, and the data from the invasion and wound healing assays were compared by Student's $t$-tests. All statistical analysis was carried out using SPSS Software for Windows 17.0. Differences were considered statistically significant at $P<0.05$. All $P$ values were twosided.

\section{CONFLICTS OF INTEREST}

The authors declare no potential conflicts of interest.

\section{GRANT SUPPORT}

This study was supported by the National Natural Science Foundation of China (No. 81070836 and No. 81470752 ) and the Beijing Natural Science Foundation of China (No. 7152066). 


\section{REFERENCES}

1. Warnakulasuriya S. Global epidemiology of oral and oropharyngeal cancer. Oral Oncol. 2009; 45:309-316.

2. Funk GF, Karnell LH, Robinson RA, Zhen WK, TRask DK, Hoffman HT. Presentation, treatment, and outcome of oral cavity cancer: a National Cancer Data Base report. Head Neck. 2002; 24:165-180.

3. World Health Organization. WHO report on the global tobacco epidemic, 2011: warning about the dangers of tobacco. Geneva: World Health Organization. 2011; 7-21.

4. Warnakulasuriya S, Sutherland G, Scully C. Tobacco, oral cancer, and treatment of dependence. Oral Oncol. 2005; 41:244-260

5. Mani SA, Guo W, Liao MJ, Eaton EN, Ayyanan A, Zhou AY, Brooks M, Reinhard F, Zhang CC, Shipitsin M, Campbell LL, Polyak K, Brisken C, et al. The epithelial-mesenchymal transition generates cells with properties of stem cells. Cell. 2008; 133:704-715.

6. Thiery JP, Acloque H, Huang RY, Nieto MA. Epithelialmesenchymal transitions in development and disease. Cell. 2009; 139:871-890.

7. Yang M, Wu M, Chiou S, Chen P, Chang S, Liu C, Teng S, Wu K. Direct regulation of TWIST by HIF-1alpha promotes metastasis. Nat Cell Biol. 2008; 10:295-305.

8. Liu Y, Gao W, Zhang D. Effects of cigarette smoke extract on A549 cells and human lung fibroblasts treated with transforming growth factor-betal in a coculture system. Clin Exp Med. 2010; 10:159-167.

9. Yu CC, Chang YC. Enhancement of cancer stem-like and epithelial-mesenchymal transdifferentiation property in oral epithelial cells with long-term nicotine exposure: reversal by targeting SNAIL. Toxicol Appl Pharmacol. 2013; 266:459-469.

10. Zhao YH, Zhang M, Yan F, Casto BC, Tang XF. Nicotineinduced upregulation of antioxidant protein Prx 1 in oral squamous cell carcinoma. Chin Sci Bull. 2013; 58:1912-1918.

11. Tang XF, Zhang XY, Zhang M. The differences expression of oxidative stress-related genes in oral cancer and precancerous cells. Beijing J Stomat. 2008; 16:308-311.

12. Zhang M, Hou M, Ge L, Miao C, Zhang J, Jing X, Shi N, Chen $\mathrm{T}$, Tang $\mathrm{X}$. Induction of peroxiredoxin 1 by hypoxia regulates heme oxygenase- 1 via NF- $\mathrm{KB}$ in oral cancer. PLoS One. 2014; 9:e105994.

13. Cha MK, Suh KH, Kim IH. Overexpression of peroxiredoxin I and thioredoxin I in human breast carcinoma. J Exp Clin Cancer Res. 2009; 28:93.

14. Yanagawa $\mathrm{T}$, Ishikawa $\mathrm{T}$, Ishii $\mathrm{T}$, Tabuchi $\mathrm{K}$, Iwasa $\mathrm{S}$, Bannai S, Omura K, Suzuki H, Yoshida H. Peroxiredoxin I expression in human thyroid tumors. Cancer Lett. 1999; 145:127-132.

15. Kim JH, Bogner PN, Baek SH, Ramnath N, Liang P, Kim HR, Andrews C, Park YM. Up-regulation of peroxiredoxin 1 in lung cancer and its implication as a prognostic and therapeutic target. Clin Cancer Res. 2008; 14:2326-2333.
16. Quan C, Cha EJ, Lee HL, Han KH, Lee KM, Kim WJ. Enhanced expression of peroxiredoxin I and VI correlates with development, recurrence and progression of human bladder cancer. J Urol. 2006; 175:1512-1516.

17. Riddell JR, Bshara W, Moser MT, Spernyak JA, Foster BA, Gollnick SO. Peroxiredoxin 1 controls prostate cancer growth through Toll-like receptor4-dependent regulation of tumor vasculature. Cancer Res. 2011; 71:1637-1646.

18. Yanagawa T, Omura K, Harada H, Ishii T, Uwayama J, Nakaso K, Iwasa S, Koyama Y, Onizawa K, Yusa H, Yoshida H. Peroxiredoxin 1 expression in tongue squamous cell carcinomas as involved in tumor recurrence. Int J Oral Maxillofac Surg. 2005; 34:915-920.

19. Kim YJ, Lee WS, Ip C, Chae HZ, Park EM, Park YM. PRX1 suppresses radiation-induced c-Jun NH2-terminal kinase signaling in lung cancer cells through interaction with the glutathione S-transferase $\mathrm{Pi} / \mathrm{c}$-Jun NH2-terminal kinase complex. Cancer Res. 2006; 66:7136-7142.

20. Rhee SG, Chae HZ, Kim K. Peroxiredoxins: a historical overview and speculative preview of novel mechanisms and emerging concepts in cell signaling. Free Radic Biol Med $2005 ; 38: 11-17$.

21. O’Leary PC, Terrile M, Bajor M, Gaj P, Hennessy BT, Mills GB, Zagozdzon A, O'Connor DP, Brennan DJ, Connor K, Li J, Gonzalez-Angulo AM, Sun HD, et al. Peroxiredoxin-1 protects estrogen receptor $\alpha$ from oxidative stress-induced suppression and is a protein biomarker of favorable prognosis in breast cancer. Breast Cancer Res. 2014; 16:R79.

22. Riddell JR, Bshara W, Moser MT, Spernyak JA, Foster BA, Gollnick SO. Peroxiredoxin 1 controls prostate cancer growth through Toll-like receptor4-dependent regulation of tumor vasculature. Cancer Res. 2011; 71:1637-1646.

23. Sun QK, Zhu JY, Wang W, Lv Y, Zhou HC, Yu JH, Xu GL, Ma JL, Zhong W, Jia WD. Diagnostic and prognostic significance of peroxiredoxin 1 expression in human hepatocellular carcinoma. Med Oncol. 2014; 31:786.

24. Ha B, Kim EK, Kim JH, Lee HN, Lee KO, Lee SY, Jang HH. Human peroxiredoxin 1 modulates TGF- $\beta 1$-induced epithelial-mesenchymal transition through its peroxidase activity. Biochem Biophys Res Commun. 2012; 421:33-37.

25. Gu K, Li MM, Shen J, Liu F, Cao JY, Jin S, Yu Y. Interleukin17-induced EMT promotes lung cancer cell migration and

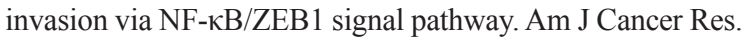
2015; 5:1169-1179.

26. Li J, Deng Z, Wang Z, Wang D, Zhang L, Su Q, Lai Y, Li B, Luo Z, Chen X, Chen Y, Huang X, Ma J, et al. Zipperinteracting protein kinase promotes epithelial-mesenchymal transition, invasion and metastasis through AKT and NF-kB signaling and is associated with metastasis and poor prognosis in gastric cancer patients. Oncotarget. 2015; 6:8323-8338. doi: 10.18632/oncotarget.3200

27. Dasgupta P, Rizwani W, Pillai S, Kinkade R, Kovacs M, Rastogi S, Banerjee S, Carless M, Kim E, Coppola D, Haura E, Chellappan S. Nicotine induces cell proliferation, invasion and epithelial-mesenchymal transition in a variety of human cancer cell lines. Int J Cancer. 2009; 124:36-45. 
28. Niimori-Kita K, Ogino K, Mikami S, Kudoh S, Koizumi D, Kudoh N, Nakamura F, Misumi M, Shimomura T, Hasegawa K, Usui $\mathrm{F}$, Nagahara $\mathrm{N}$, Ito $\mathrm{T}$. Identification of nuclear phosphoproteins as novel tobacco markers in mouse lung tissue following short-term exposure to tobacco smoke. FEBS Open Bio. 2014; 4:746-54.

29. Arredondo J, Chernyavsky AI, Grando SA. Nicotinic receptors mediate tumorigenic action of tobacco-derived nitrosamines on immortalized oral epithelial cells. Cancer Biology and Therapy. 2006; 5:511-517.

30. Dash B, Li MD. Analysis of rare variations reveals roles of amino acid residues in the $\mathrm{N}$-terminal extracellular domain of nicotinic acetylcholine receptor (nAChR) alpha6 subunit in the functional expression of human alpha6*-nAChRs. Mol Brain. 2014; 7:35.

31. Selwyn S. Jayakar and Joseph F. Margiotta. Abelson Family Tyrosine Kinases Regulate the Function of Nicotinic Acetylcholine Receptors and Nicotinic Synapses on Autonomic Neurons. Mol Pharmacol. 2011; 80:97-109.

32. Brown KC, Perry HE, Lau JK, Jones DV, Pulliam JF, Thornhill BA, Crabtree CM, Luo H, Chen YC, Dasgupta P. Nicotine induces the up-regulation of the $\alpha 7$-nicotinic receptor ( $\alpha 7-n A C h R)$ in human squamous cell lung cancer cells via the Sp1/GATA protein pathway. J Biol Chem. 2013; 288: 33049-33059.

33. Nieh S, Jao SW, Yang CY, Lin YS, Tseng YH, Liu CL, Lee TY, Liu TY, Chu YH, Chen SF. Regulation of tumor progression via the SNAIL-RKIP signaling pathway by nicotine exposure in head and neck squamous cell carcinoma. Head Neck. 2015; 37:1712-1721.

34. Niu W, Zhang $M$, Jing $X$, Dong R, Zhang J, Tang X. Expression of $\alpha 3 \mathrm{nAChR}$ and $\alpha 7 \mathrm{nAChR}$ in oral cancer. Beijing J Stomat. 2014; 22:307-310.

35. Thiery JP, Sleeman JP. Complex networks orchestrate epithelial-mesenchymal transitions. Nat Rev Mol Cell Biol 2006; 7:131-142.

36. Smith A, Teknos TN, Pan Q. Epithelial to mesenchymal transition in head and neck squamous cell carcinoma. Oral Oncol. 2013; 49:287-92.

37. Hayden MS, Ghosh S. Shared principles in NF-kappaB signaling. Cell. 2008; 132:344-62.

38. Scheel C, Weinberg RA. Cancer stem cells and epithelialmesenchymal transition: concepts and molecular links. Semin Cancer Biol. 2012; 22:396-403. 